Abstract P10 Table 1 Extra-criteria clinical manifestations of APS and APLs-carriers

\begin{tabular}{|c|c|c|c|c|c|c|c|c|c|c|c|}
\hline & \multirow{2}{*}{$\begin{array}{l}\text { PAPS } \\
(\mathrm{N}=27)\end{array}$} & \multicolumn{3}{|c|}{ Secondary APS(N=34) } & \multirow[b]{2}{*}{ Total } & \multicolumn{4}{|c|}{ APLs persist positive( $(N=119)$} & \multirow[b]{2}{*}{ Total } & \multirow{2}{*}{$\begin{array}{l}\text { Total } \\
\text { ( } N=180)\end{array}$} \\
\hline & & $\begin{array}{c}\text { SLE } \\
(N=20)\end{array}$ & $\begin{array}{l}\text { CTD } \\
(\mathrm{N}=9)\end{array}$ & $\begin{array}{c}\text { Non-AID } \\
(N=5)\end{array}$ & & $\begin{array}{c}\text { SLE } \\
(\mathrm{N}=40)\end{array}$ & $\begin{array}{c}\text { CTD } \\
(\mathrm{N}=26)\end{array}$ & $\begin{array}{l}\text { Non-AID } \\
(N=15)\end{array}$ & $\begin{array}{l}\text { Unknown } \\
(\mathrm{N}=38)\end{array}$ & & \\
\hline Hematological & 6 & 11 & 5 & 2 & 18 & 19 & 2 & 4 & 8 & 33 & $57(31.7 \%)$ \\
\hline Thrombocytopenia & 6 & 10 & 4 & 1 & 15 & 18 & 2 & 4 & 8 & 32 & $53(29.4 \%)$ \\
\hline Haemolytic anaemia & 1 & 3 & 2 & 2 & 7 & -6 & 0 & 0 & 0 & 6 & $14(7.8 \%)$ \\
\hline Livedo reticularis & 0 & 1 & 1 & 0 & 2 & 1 & 0 & 0 & 0 & 1 & $3(1.7 \%)$ \\
\hline APS nephropathy & 2 & 1 & 2 & 1 & 4 & 0 & 0 & 0 & 0 & 0 & $6(3.3 \%)$ \\
\hline $\begin{array}{l}\text { Valvular heart } \\
\text { disease }\end{array}$ & 2 & 6 & 1 & 0 & 7 & 4 & 0 & 1 & 1 & 6 & $15(8.3 \%)$ \\
\hline $\begin{array}{l}\text { neurological } \\
\text { manifestations }\end{array}$ & 3 & 3 & 4 & 1 & 8 & 4 & 1 & 0 & 2 & 7 & $18(10 \%)$ \\
\hline Thrombophlebitis & 0 & 2 & 0 & 1 & 3 & 0 & 2 & 1 & 0 & 3 & $6(3.3 \%)$ \\
\hline Total & 9 & 13 & 6 & 2 & 21 & 21 & 5 & 5 & 11 & 42 & $72(40 \%)$ \\
\hline
\end{tabular}

Conclusions The most common extra-criteria manifestations are thrombocytopenia, non-vascular neurological manifestations and valvular heart disease. And they can be the independent clinical feature of APLs without thrombotic events or Pregnancy morbidities.

\section{P11 EARLY EFFICIENT ANTICOAGULATION IMPROVES THE LONG-TERM PROGNOSIS IN PATIENTS WITH ANTIPHOSPHOLIPID SYNDROME ASSOCIATED PORTAL VEIN THROMBOSIS}

Jiuliang Zhao, Hanxiao You, Xinping Tian, Mengtao Li, Xiaofeng Zeng. Dept. of Rheumatology, Peking Union Medical College Hospital, Beijing, China

\subsection{6/lupus-2020-eurolupus.60}

Background Portal vein thrombosis (PVT) is a rare and severe clinical phenotype of antiphospholipid syndrome (APS) with a poor prognosis. Anticoagulation therapy is efficient, but is associated with potentially severe side-effects, especially bleeding episodes. The aim of this study was to retrospectively analyze our single center experience on long-term anticoagulation in APS patients presenting a PVT.

Methods A retrospective study of APS patients with PVT from 2012 to 2019 was conducted using the Hospital Information System of Peking Union Medical College Hospital. Basic clinical history and complications were collected. Regular imaging was performed to monitor the outcome of PVT. The recanalization rate of the PVT after anticoagulation was analyzed using the survival analysis.

Results A total of 28 patients with APS-PVT were enrolled, 5 males and 23 females, with the median age 37 years (range 17-63 years), and the mean follow-up was 3 years (range, $0.5-7$ years). 8 cases were acute thrombosis, 16 cases chronic thrombosis, and 4 cases portal vein cavernoma. The first symptoms presented as abdominal distention (14/28) or pain $(7 / 28)$ and blood system involvements (22/28, anemia or thrombocytopenia), while presentation with variceal bleeding (4 cases) was less common, and 2 patients were asymptomatic. Triple aPLs positive in 7 cases. 10 cases began efficient anticoagulation therapy immediately at the diagnosis of thrombus. 8 patients got thrombus recanalization. 3 patients got recurrence. 5 patients died. Survival analysis revealed that effective anticoagulation could increase recanalization rate significantly (log rank $\mathrm{p}=0.001$ ), as shown in figure 1 .

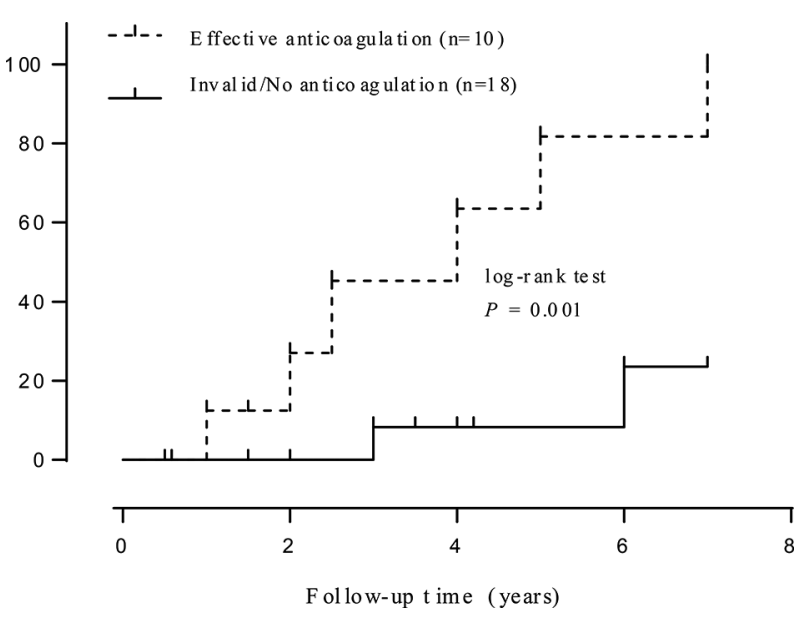

Abstract P11 Figure 1 Difference of accumulated recanalization rate between receiving immediate effective anticoagulation group and invalid anticoagulation group

Conclusions PVT usually had insidious onset with atypical clinical symptoms and easily be misdiagnosed. Early diagnosis and efficient anticoagulation treatment can bring thrombus recanalization thereby significantly improving the prognosis.

\section{P12 SERUM LEVELS OF SOLUBLE ST2 AND THEIR ASSOCIATION WITH MICROPARTICLES AND DISEASE ACTIVITY IN SYSTEMIC LUPUS ERYTHEMATOSUS}

${ }^{1}$ Karen Álvarez, ${ }^{1}$ Manuela Osorio, ${ }^{1}$ Tulio Lopera, ${ }^{2}$ Karen Dubois-Camacho, ${ }^{2}$ Marcela A Hermoso, 'Gloria Vásquez. 'Grupo de Inmunología Celular e Inmunogenética (G/CIG), Sede de investigación Universitaria (SIU), Facultad de Medicina, Universidad de Antioquia, Medellin, Colombia; ${ }^{2}$ Laboratorio de Inmunidad Innata, Facultad de Medicina, Universidad de Chile, Santiago de Chile, Chile

\subsection{6/lupus-2020-eurolupus.61}

Background ST2 is an IL-33 receptor (a member of the IL-1 receptor family), existing in a transmembrane form (ST2L) and is also alternatively spliced to produce a secreted soluble form (sST2) and a membrane-anchored variant without the immunoglobulin-like motif (ST2V). High levels of sST2 have been reported in inflammatory diseases, including systemic lupus erythematosus (SLE). Additionally, higher levels of 